\title{
RESTABELECIMENTO DA CONFIABILIDADE OPERACIONAL DO GASÔMETRO DE GÁS DE ALTO FORNO "BFG" DA THYSSENKRUPP CSA (TKCSA)*
}

Alencar de Andrade Soares ${ }^{1}$ Carlos Roberto da Silva ${ }^{2}$ Marcus Vinicius Buarque ${ }^{3}$ David Arthur Swan

\section{Resumo}

Este trabalho tem como objetivo descrever as ações que foram tomadas pela TKCSA com o objetivo de restabelecer a capacidade operacional plena do Gasômetro (BFG), pela sua estabilidade e, por conseguinte a sua continuidade operacional. Desde seu start-up, ambos os Gasômetros apresentaram vários problemas que impediram sua operação em plena capacidade; provocaram várias paradas para realinhamento, rebalanceamento, bem como repopeamento. Estas ocorrências interferiram fortemente na Geração de energia do complexo, devido a instabilidade dos Gasômetros, causada por irregular movimentação do pistão, provocando sua descentralização e desnivelamentos fora das tolerâncias aceitáveis, o que levou a TKCSA a limitar a operação dos Gasômetros e, mesmo assim ; sempre que descentralizava e ou desnivelava, era necessário novos ajustes (repopeamento e rebalanceamento). Tais eventos nestes importantes equipamentos, levaram a CSA a tomar várias ações conforme preconiza o IGEM (Instituition of Gas Engineer) passando por reparos estruturais e culminando com a troca do sistema de selagem dos Gasômetros.

Palavras-chave: Segurança; Gasômetro; Repopeamento; Rebalanceamento; Gás de alto forno "BFG".

\section{RE-ESTABLISHING OF OPERATIONAL RELIABILITY OF THE TKCSA'S BLAST FUNNACE GASHOLDER}

\section{Abstract}

This work aims to describe the actions that were taken by the CSA in order to reestablish the full operational capacity of the Gasholder (BFG), for its stability and therefore its operational continuity. Since its start-up, both Gasholders had several problems that impeded its full operational capacity; caused several stops for realignment, rebalancing and repoping. These occurrences strongly interfere in the power generation of the complex, due Gasholders's instability, caused by irregular movement of the piston, causing its decentralization and unbalancing out the acceptable tolerances, leading to TKCSA to limit the operational capacity of the Gasholders, and even then; whenever that centralization was out and or balance was out, it was necessary new settings (repoping and rebalancing). Such events at this important equipment, led the CSA to take various actions as recommendation of IGEM (Instituition of Gas Engineer) undergoing structural repairs and culminating with the change of the Gasholders membrane (seal system).

Keywords: Safety; Gasholder; Repoping; Rebalancing; Blast furnance gas "BFG".

Especialista Técnico em Utilidades, ThyssenKrupp, CSA, Rio de Janeiro, RJ, Brasil.

Supervisor de Distribuição de Utilidades, ThyssenKrupp, CSA, Rio de Janeiro, RJ, Brasil.

Coordenador de Manutenção Utilidades, ThyssenKrupp, CSA, Rio de Janeiro, RJ, Brasil.

Coordenador de Engenharia e Infra-estrutura, ThyssenKrupp, CSA, Rio de Janeiro, RJ, Brasil. 


\section{INTRODUÇÃO}

Como toda Usina Integrada; a TK CSA projetou e instalou em seu complexo, dois Gasômetros tipo Wiggins; um para receber gás do Alto Forno (BF) e o outro, gás da Aciaria (BOF) com o objetivo de estabilizar a pressão do Gás para o complexo nos momentos de instabilidade na produção (Altos Fornos e Aciaria) e ou nos consumidores, cujo principal, maior consumidor, é a Power Plant (Planta Geradora de Energia Elétrica). Os Gasômetros têm capacidade projetada e instalada de $100.000 \mathrm{~m}^{3}$ de gás. Este Gasômetro, com tal especificação, tamanho, volume $\mathrm{x}$ pressão, constitui um equipamento cujo projeto e construção, requerem cuidados especiais de modo a garantir a desempenho operacional e evitar acidentes. Durante o período de comissionamento, foram registrados alguns problemas, tipo: Membrana muito grande (vide figura 1), Jamais vista anteriormente em outros Gasômetros, com especificações similares, inclinações excessivas do pistão, redução da clearence (espaçamento entre pistão e costado), cada vês maiores, culminando com a batida do pistão contra o costado e o mesmo ficando tão encostado contra as paredes, que na tentativa de reposicionar o pistão foi utilizado vários recursos, que entre eles até pneus de caminhão, Air Bags com um trabalho muito cansativo e perigoso (porem com contemplado todo aspecto de segurança) no intuito de não rasgar a membrana, o que demandaria de um tempo de restabelecimento maior ou até mesmo sem condições de recuperação. Na segunda etapa, após vários ajustes, balanceamento efetuado pela empresa especializada; chegou a uma conclusão da necessidade de realmente efetuar o POP do Gasômetro devido a suspeita de que nunca havia sido efetuado, uma vez que várias dobras remanesciam na fixação inferior e também na curvatura superior da membrana. Então na tentativa de retirar as dobras e efetuar o POP, foi elevado o pistão do Gasômetro para níveis superiores a $100 \%$. Não obtivemos sucesso com essa tentativa, e como não havia mais possibilidade de elevação do nível do Gasômetro (limite físico e por segurança, esta atividade foi abortada (nível Gasômetro em 101,25\%), porem as dobras ainda continuavam puxando o pistão para o casco. Foi estabelecida uma terceira etapa quando foi adaptada uma fixação tipo orelhas, cujo nome em inglês é special lugs, distribuída em todo o diâmetro da membrana com o devido espaçamento entre elas, com o objetivo de pré-esticá-la com ainda em zero\%, de modo a não ter necessidade de fazê-lo em 100\%; este procedimento foi denominado de pré pop. $\mathrm{Na}$ terceira etapa com maior número de observações e dados registrados, revelou-nos que o pistão, ainda continuava lentamente, se deslocando do centro do gasômetro, se aproximando em direção ao casco. A aproximação se tronava um risco para a segurança do equipamento bem como para a sua continuidade operacional; então ficou estabelecido em limite mínimo admissível, que após ser atingido, exigia que o gasômetro fosse tirado de operação para que o Gasômetro pudesse ser 'rebalanceado e realinhado' novamente.

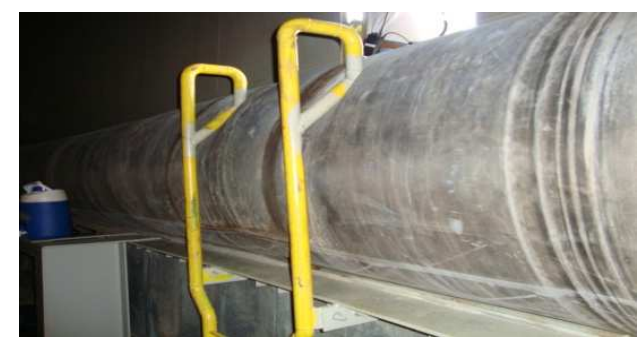

Figura 1. Membrana com o Gasômetro em 0\%, tamanho que impossibilitava o acesso o interior do Gasômetro. 


\section{MATERIAIS E MÉTODOS}

O Método para avaliação do problema utilizado foi o PDCA (Planejar, Fazer, Checar e avaliar).

\section{1 (P) Planejamento}

Uma inspeção interna no Gasômetro BFG foi planejada para certificação dos valores informados via sistema Laser (sala de controle), que estava enviando vários sinais de alarmes de desnivelamento do pistão do Gasômetro e também avaliar as condições operacionais quanto a Clearence e comportamento da membrana. Tal inspeção nos trouxe preocupações devido as informações coletadas (figura 2).

\begin{tabular}{|c|c|c|c|c|c|}
\hline OBSERVAĢö̌s GRALS & САBO & $\begin{array}{l}\text { NvE } \\
25 \mathrm{~mm}\end{array}$ & vaвiç̧̄o & $\begin{array}{c}\text { AFASTAMENTO } \\
\text { FENDER } \\
\begin{array}{c}\text { CSSARD } \\
600 \mathrm{~mm}\end{array} \\
200 \%\end{array}$ & AUSTE \\
\hline \multirow{12}{*}{$\begin{array}{l}\text { Feito medição na porta no } 4 \text {, acompanhada pelo Mr RUSSEL. Não houve nenhum } \\
\text { ajuste nos cabos, foi recomendado abaixar o pistão até a porta no } 3 \text {, para verificar se } \\
\text { houve melhora de afastamento e nivelamento no cabo no } 5 \text {. }\end{array}$} & 1 & 130 & -34 & 545 & \\
\hline & 2 & 165 & 50 & 385 & \\
\hline & 3 & 175 & 80 & 290 & \\
\hline & 4 & 190 & 110 & 210 & \\
\hline & 5 & 185 & 103 & 125 & \\
\hline & 6 & 173 & 79 & 185 & \\
\hline & 7 & 164 & & 235 & \\
\hline & 8 & 115 & & 355 & \\
\hline & 9 & 95 & & 485 & \\
\hline & 10 & 80 & & 585 & \\
\hline & 11 & 82 & & 575 & \\
\hline & 12 & 94 & & 595 & \\
\hline \multicolumn{6}{|l|}{ ASSINATURAS: } \\
\hline \multicolumn{6}{|l|}{ Técnico de operação - Carlos Roberto / Rivaldo e Daniel } \\
\hline \multicolumn{6}{|l|}{ Técnico de Manutenção } \\
\hline \multicolumn{6}{|l|}{ Supervisor operação - Alencar de Andrade Soares } \\
\hline
\end{tabular}

Figura 2 Planilha de inspeção mostrando clearence menor que $200 \mathrm{~mm}$ nos cabos 5 e 6

Com os resultados acima, ficou claro que o Gasômetro estava operando completamente fora das tolerâncias pré-estabelecidas, tais como:

a) Clearence $>200 \mathrm{~mm} \mathrm{e}<600 \mathrm{~mm}$

b) Desnivelamento $40 \mathrm{~mm}$

Então foi limitado o curso do pistão do Gasômetro para 50\% e acionado assistência especializada. Após inspeção com a empresa especializada, foi efetuado várias tentativas de rebalanceamento e sem sucesso, foi recomendado então a segunda redução do curso do pistão para 36\% devido ao alto risco para o equipamento.

\section{2 (D) Fazer}

Mediante recomendação do especialista foi efetuado o procedimento de repopear o Gasômetro (despressurizar e elevar a 100\% para esticar a membrana), porem durante esta operação o pistão bateu no costado (figura 3), quando foi aplicado recursos internos para recentralizar, com muita dificuldade devido ao peso e pressão 


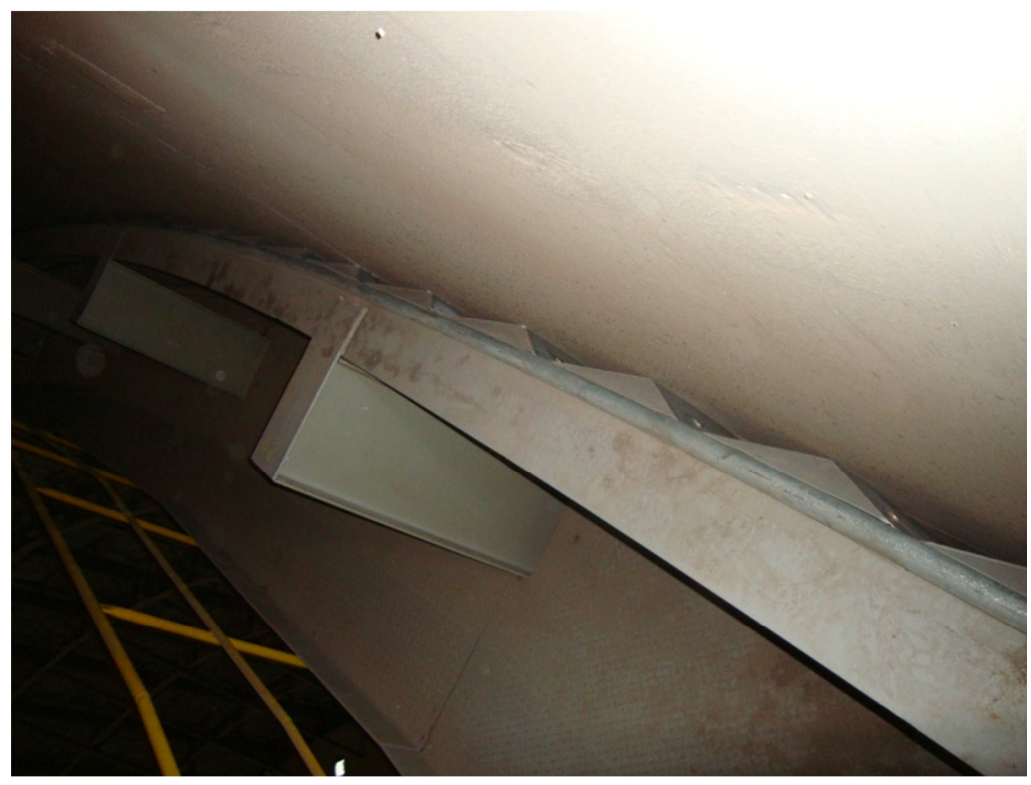

Figura 3. Pistão encostado no costado após batida

\section{3 (D) Fazer}

Durante o procedimento de repopear o Gasômetro, muitas dobras na membrana ainda remanesciam então, na tentativa de retirar as dobras na membrana, foi elevado o pistão do Gasômetro para o maior nível possível, porem sem sucesso, evidenciando a falta do Pop (causa da descentralização do pistão e consequente batida no costado) vide figura 4.

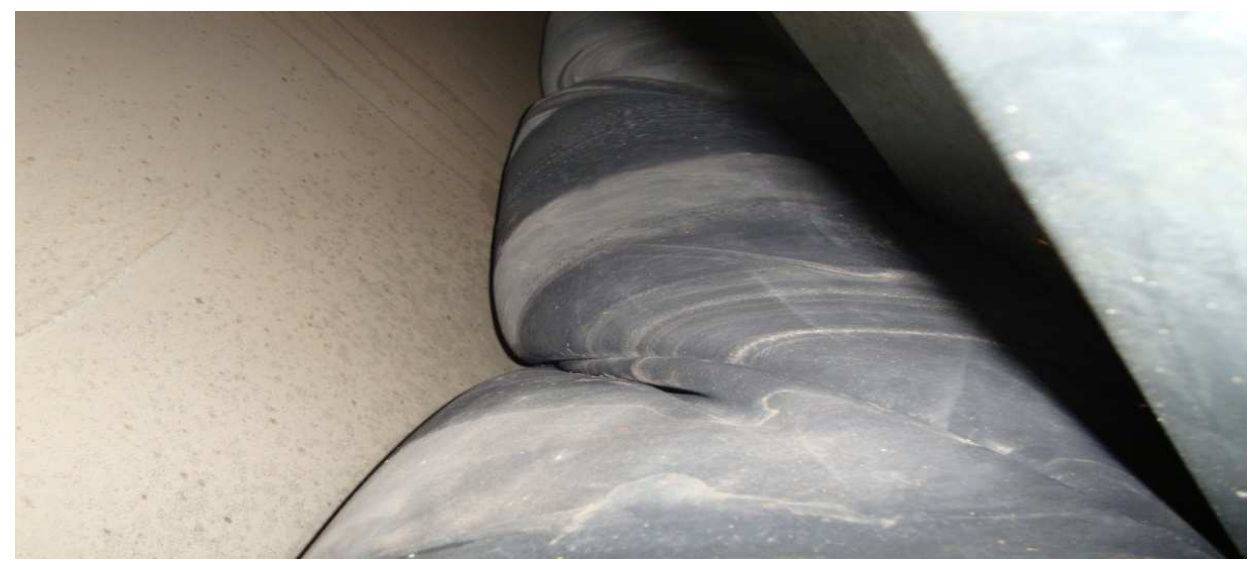

Figura 4. Dobras na membrana provocando a descentralização do pistão

\section{4 (D) Fazer}

Após estudo dos especialistas, foi idealizado e efetuado a instalação dos special lugs conforme descrito acima com objetivo de efetuar o esticamento da membrana em níveis mais baixo $0 \%$, sem correr risco de novo acidente, vide figura 5 . 


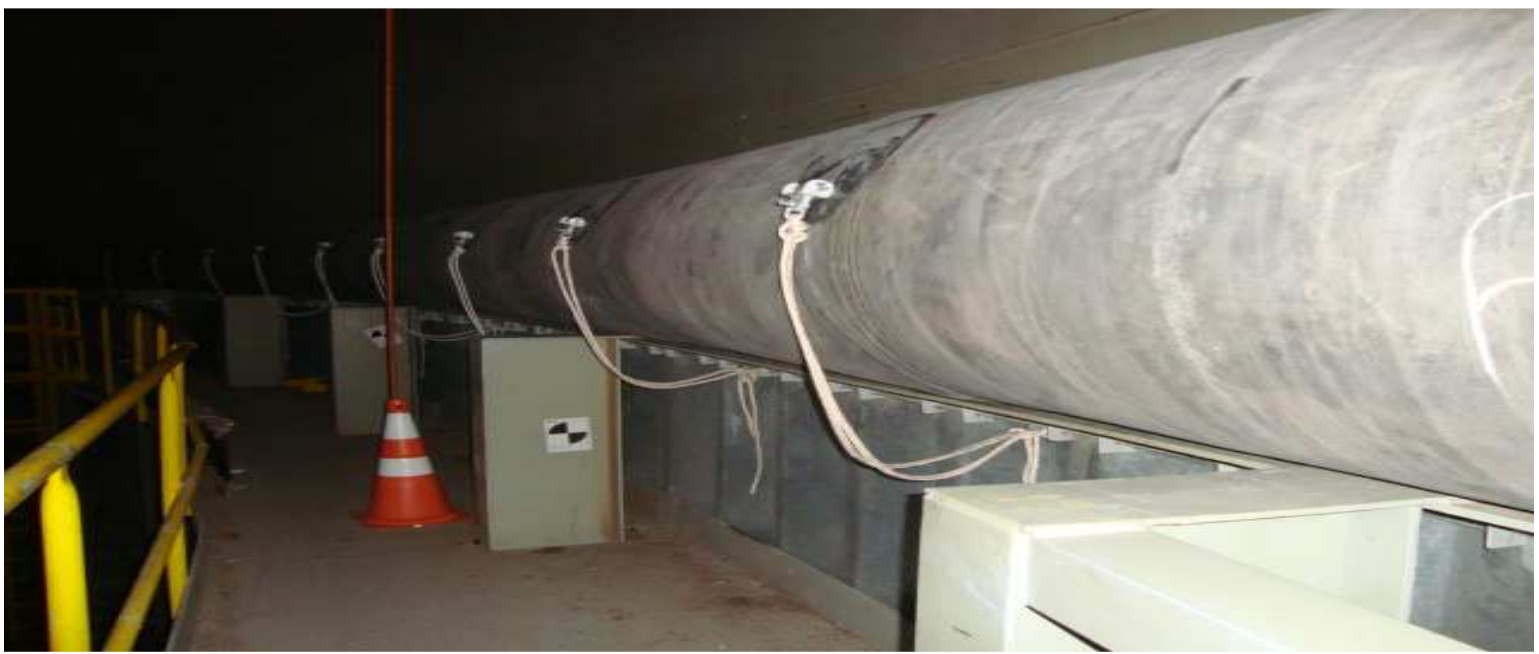

Figura 5. Orelhas amarradas evitando que a membrana perdesse a formatação facilitando o POP

\section{RESULTADOS}

\section{1 (C) Checar - Cheque e acompanhamento das ações}

Mesmo com todas as intervenções mostradas acima, o Gasômetro continuou a apresentar descentralização e alarmes de desnivelamento alto conforme (Tabela1).

Tabela 1 performance do Gasômetro após ajustes

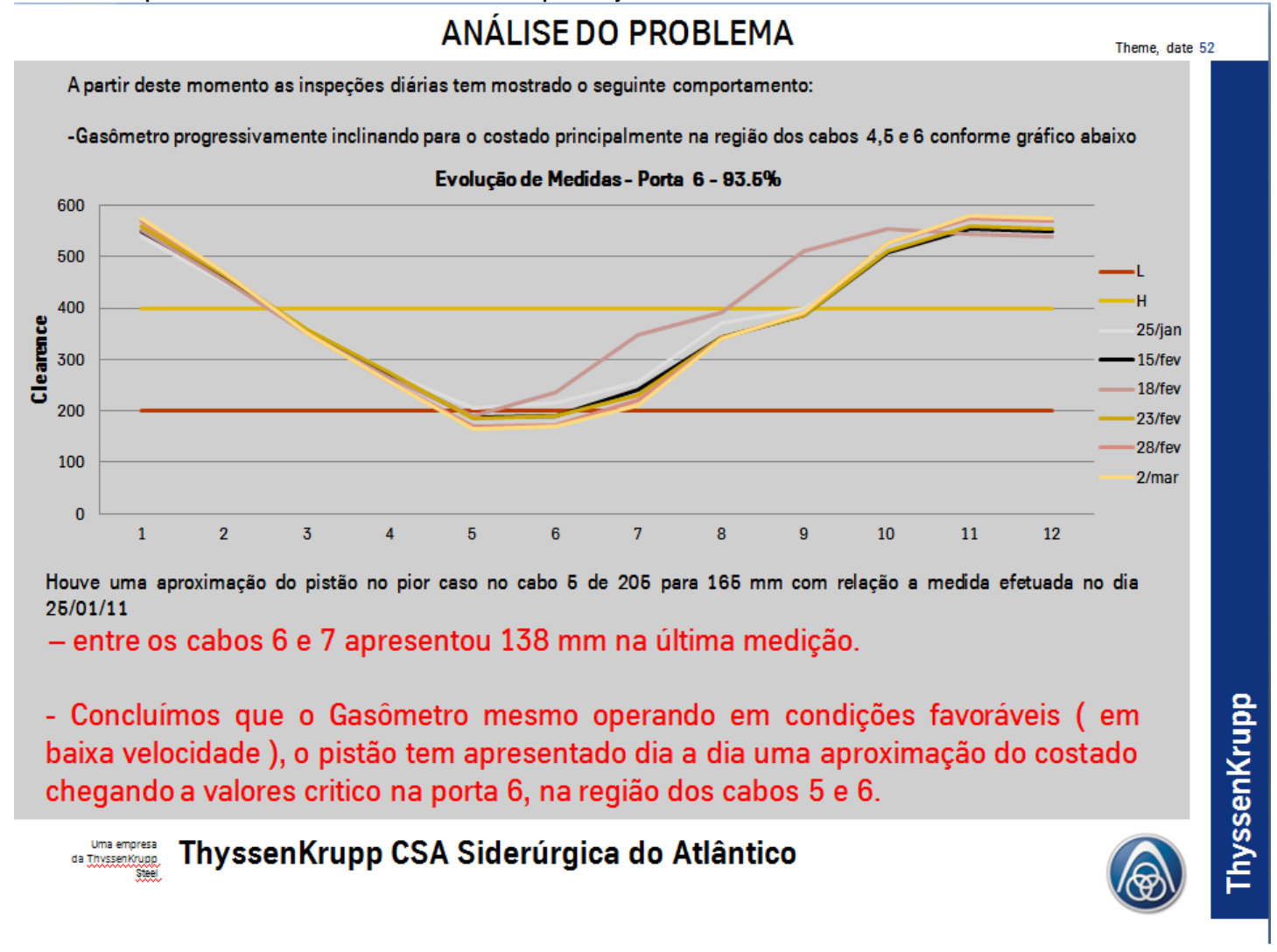




\section{2 (D) Fazer - Ação - Reforço estrutural e Troca da Membrana.}

Ficou evidenciado que devido o tamanho da membrana, não era possível efetuar o procedimento de POP de maneira efetiva, mesmo com o Special Lugs; então foi estudado, projetado e instalado nova membrana com 1,4m mais curta; contudo mantendo ainda a segurança do equipamento pela estabilidade do Gasômetro nos níveis elevados (acima de 98\%), que era o receio do fabricante. Para garantir esta estabilidade em níveis mais altos bem como segurança, o limite superior foi reduzido em $1300 \mathrm{~mm}$, de modo que o ajuste do sistema mecânico de alivio de gás (última redundância) também foi reposicionado. Paralelo a estas atividades, foi efetuado reforço nas estruturas do pistão do Gasômetro uma vez que nas inspeções foi encontrado solda fora da especificação, falta de solda e trincas conforme em vários pontos, o que demandou grande quantidade de trabalhadores ( 80 pessoas no pico) dentro do Gasômetro efetuando atividades paralela de desmontagem/ montagem, corte e solda. Toda a atividade foi concluída com sucesso total e sem acidentes.

\section{4 (A) AVALIAÇÃO - RESULTADOS}

Após os trabalhos realizados e com o equipamento operando de maneira estável e confiável e em plena capacidade (sem restrições), efetuamos a medição do quanto perdemos e quanto estamos evitando perder com restrições operacionais do equipamento, paradas para ajustes (balanceamento e realinhamento) e reparos; por conseguinte maior consumo de Gás Natural para suprir a matriz energética da empresa pela falta do Gás que era queimado no flare nos momentos de restrição do Gasômetro bem como as paradas e também custo com Energia Elétrica. A tabela abaixo (tabela 2) evidencia estes indicadores; o que, após as intervenções supra citadas, não temos mais a necessidade de gastar.

Tabela 2 - fonte TKCSA

\begin{tabular}{|c|c|}
\hline CONSUMO DE GÁS NATURAL AO LONGO DO PERÍODO & $184.453,14 \mathrm{~m}^{3}$ \\
\hline AQUISIÇÃO DE ENERGIA ELÉTRICA AO LONGO DO PERÍODO & $173.408 \mathrm{MW}$ \\
\hline
\end{tabular}

\section{CONCLUSÃO}

Após a troca da membrana e o reforço da estrutura do pistão, o Gasômetro voltou a operar em sua capacidade plena, sem nenhum problema quanto a descentralização e desnivelamento, garantindo a continuidade operacional e possibilidade de parar o Gasômetro para qualquer atividade com retorno à operação com menor tempo e menor custo vide comportamento (figura 6) 


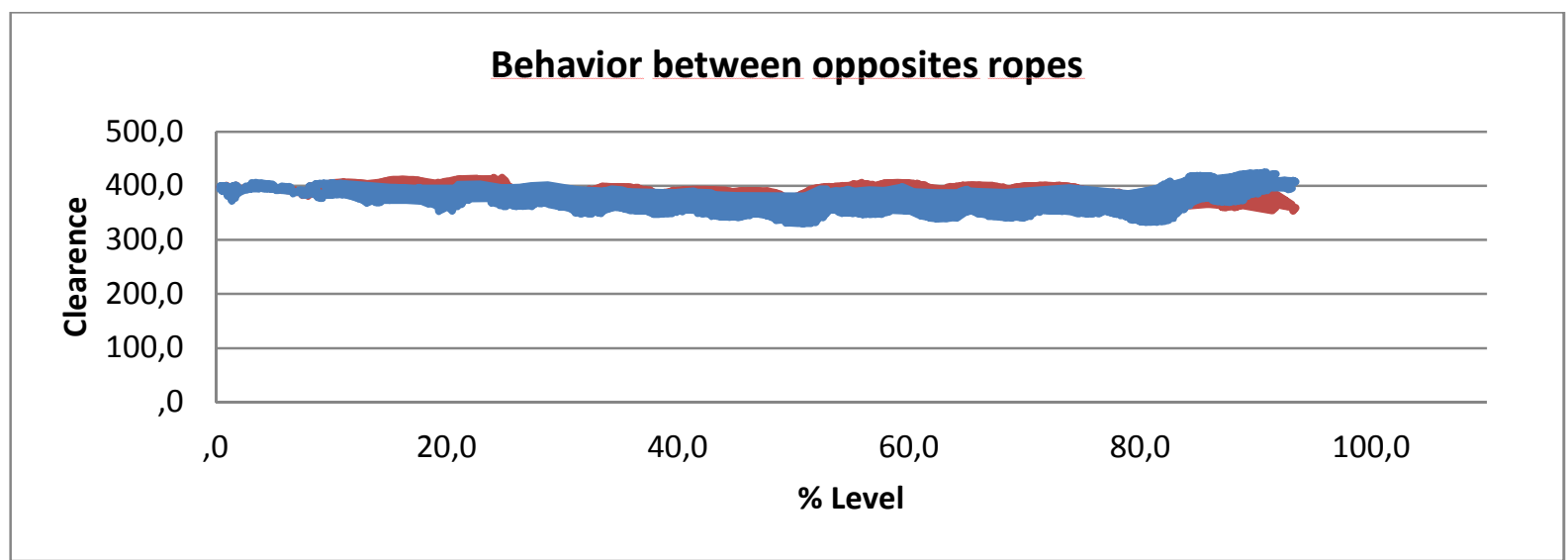

Figura 6 Perfil do Afastamento do Pistão do Casco (pelo Radar)

Pode-se confirmar a perfeita estabilidade operacional do Gasômetro apresentada nos gráfico acima. A solução foi alterar a geometria da membrana, o componente flexível e efetuar o reforço na estrutura do pistão.

\section{BIBLIOGRAFIA}

1. IGEM - Institute of Gas Engineers and Managers - SR4, Edition 3 - Variable Volume Gasholders Storing Lighter than Air Gases, 2010

2. Relatório das Medidas Corretivas Fase 1, Resultados de Testes no Gasômetro BOF Ferrostaal - Offner, 2012 